Article

\title{
Aortic Oxidative Stress, Inflammation and DNA Damage Following Pulmonary Exposure to Cerium Oxide Nanoparticles in a Rat Model of Vascular Injury
}

\author{
Abderrahim Nemmar ${ }^{1, *}$, Suhail Al-Salam ${ }^{1}$, Sumaya Beegam ${ }^{1}$, Priya Yuvaraju ${ }^{1}$ and \\ Badreldin H. Ali ${ }^{2}$ \\ 1 Department of Physiology, College of Medicine and Health Sciences, United Arab Emirates University, \\ P.O. Box 17666, Al Ain, Abu Dhabi, UAE \\ 2 Department of Pharmacology, College of Medicine \& Health Sciences, Sultan Qaboos University, P.O. Box 35, \\ Muscat 123, Al-Khoud, Oman \\ * Correspondence: anemmar@uaeu.ac.ae
}

Received: 17 June 2019; Accepted: 29 July 2019; Published: 17 August 2019

\begin{abstract}
Pulmonary exposure to cerium oxide nanoparticles $\left(\mathrm{CeO}_{2} \mathrm{NPs}\right)$ can occur either at the workplace, or due to their release in the environment. Inhaled $\mathrm{CeO}_{2} \mathrm{NPs}$ are known to cross the alveolar-capillary barrier and reach various parts of the body, including the vasculature. The anticancer drug cisplatin (CP) causes vascular damage. However, the effects $\mathrm{CeO}_{2} \mathrm{NPs}$ on vascular homeostasis in a rat model of $\mathrm{CP}$-induced vascular injury remain unclear. Here, we assessed the impact and underlying mechanism of pulmonary exposure to $\mathrm{CeO}_{2} \mathrm{NPs}$ on aorta in rats given a single intraperitoneal injection of cisplatin $(\mathrm{CP}, 6 \mathrm{mg} / \mathrm{kg})$ to induce vascular damage. Six days later, the rats were intratracheally instilled with either $\mathrm{CeO}_{2} \mathrm{NPs}(1 \mathrm{mg} / \mathrm{kg})$ or saline (control), and various variables were studied $24 \mathrm{~h}$ thereafter in the aortic tissue. The concentration of reduced glutathione and the activity of catalase were significantly increased in the $\mathrm{CP}+\mathrm{CeO}_{2} \mathrm{NPs}$ group compared with both the $\mathrm{CP}+$ saline and the $\mathrm{CeO}_{2} \mathrm{NPs}$ groups. The activity of superoxide dismutase was significantly decreased in the $\mathrm{CP}+\mathrm{CeO}_{2} \mathrm{NPs}$ group compared with both the $\mathrm{CP}+$ saline and $\mathrm{CeO}_{2} \mathrm{NPs}_{\text {groups }}$ The expression of nuclear factor erythroid-derived 2-like 2 (Nrf2) by the nuclei of smooth muscles and endocardial cells assessed by immunohistochemistry was significantly augmented in $\mathrm{CeO}_{2} \mathrm{NPs}$ versus saline, in $\mathrm{CP}+$ saline versus saline, and in $\mathrm{CP}+\mathrm{CeO}_{2} \mathrm{NPs}$ versus $\mathrm{CeO}_{2} \mathrm{NPs}$. Moreover, the concentrations of total nitric oxide, lipid peroxidation and 8-hydroxy-2-deoxyguanosine were significantly elevated in the $\mathrm{CP}+\mathrm{CeO}_{2} \mathrm{NPs}$ group compared with both the $\mathrm{CP}+$ saline and the $\mathrm{CeO}_{2}$

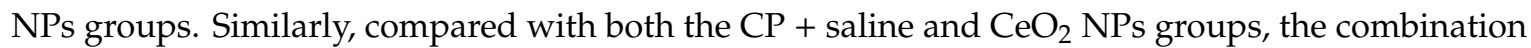
of $\mathrm{CP}$ and $\mathrm{CeO}_{2} \mathrm{NPs}$ significantly elevated the concentrations of interleukin- 6 and tumour necrosis factor- $\alpha$. Additionally, aortic DNA damage assessed by Comet assay was significantly increased in $\mathrm{CeO}_{2} \mathrm{NPs}$ compared with saline, and in $\mathrm{CP}+$ saline versus saline, and all these effects were significantly aggravated by the combination of $\mathrm{CP}$ and $\mathrm{CeO}_{2} \mathrm{NPs}$. We conclude that pulmonary exposure to $\mathrm{CeO}_{2} \mathrm{NPs}$ aggravates vascular toxicity in animal model of vascular injury through mechanisms involving oxidative stress, Nrf2 expression, inflammation and DNA damage.
\end{abstract}

Keywords: Cerium oxide nanoparticles; aorta; inflammation; oxidative stress; Nrf2; DNA damage

\section{Introduction}

Nanotechnology develops particles $<100 \mathrm{~nm}$ in size in at least one dimension with unique physical and chemical characteristics. These nanoparticles are being used in many fields, including industrial, medical, information, and communication technologies, implying wide use in consumer 
and industrial products [1]. However, the manufacturing of novel nanomaterials frequently occurs in the absence of relevant studies on the possible pathophysiological effects on human health [2-4].

Among the various nanomaterial products, cerium oxide $\left(\mathrm{CeO}_{2}\right)$ is an important compound, as it is used in solar and fuel cells, gas sensors, oxygen pumps, polishing media, and as a fuel additive to decrease emanations of gaseous products of incomplete combustion, and enhance fuel burning efficiency [5-7]. In addition to human exposure in the workplace during manufacturing, it has been reported that $\mathrm{CeO}_{2}$ nanoparticles $\left(\mathrm{CeO}_{2} \mathrm{NPs}\right)$ are discharged into ambient air from diesel engines that use cerium compounds as a diesel fuel catalyst, leading to exposure of humans by inhalation [5-7].

In addition to causing lung toxicity, inhaled $\mathrm{CeO}_{2} \mathrm{NPs}$ have been shown to induce secondary systemic effects by their ability to pass through the alveolar-capillary barrier and/or $\mathrm{CeO}_{2} \mathrm{NPs}$-induced release of reactive oxygen species and inflammatory mediators from the alveoli into the circulation, affecting various distant sites, including the vascular tissue [8,9]. Moreover, human and animal investigations have established that the pathophysiological effects of nanoparticles in general are aggravated in vulnerable patients and animals with pre-existing vascular diseases $[3,10,11]$. However, as far as we are aware, the impact of pulmonary exposure to $\mathrm{CeO}_{2} \mathrm{NPs}$ on the aorta in an animal model of vascular injury induced by cisplatin $(\mathrm{CP})$ has not been reported before. $\mathrm{CP}$ is an effective anticancer drug utilized in the treatment of several solid tumours [12-14]. However, its usage is associated with many severe adverse effects, particularly nephrotoxicity and vascular dysfunction [12-14]. Even though the mechanisms of action of $\mathrm{CP}$ are not fully understood, several studies have reported that $\mathrm{CP}$-induced cytotoxicity involves oxidative stress and inflammation, and causes vascular toxicity including myocardial infarction and stroke [12-14]. Vascular dysfunction can progress into systemic vascular injury, which is principally classified into macrovascular disease comprising aortic atherosclerosis and microangiopathy. In the present study, the rat aorta was used to investigate the pathophysiological alterations at macrovascular level. The aorta was also chosen because such large vessels can be easily collected, making it possible to assess the possible aggravating effects of the combination of pulmonary exposure to $\mathrm{CeO}_{2} \mathrm{NPs}$ and $\mathrm{CP}$ treatment on aortic oxidative stress, inflammation and DNA damage. The latter events are observed in the early stage of aortic atherosclerosis [12-14].

Therefore, the aim of this report is to assess the impact and mechanism of lung exposure to $\mathrm{CeO}_{2} \mathrm{NPs}$ on the aorta of healthy rats, and rats with $\mathrm{CP}$-induced vascular damage by measuring several markers of inflammation (interleukin-6 (IL-6) and tumour neurosis factor- $\alpha$ (TNF $\alpha$ )), oxidative stress (reduced glutathione (GSH), catalase (CAT), superoxide dismutase (SOD), nuclear factor erythroid-derived 2-like 2 (Nrf2) expression, total nitric oxide (NO), lipid peroxidation (LPO) and 8-hydroxydeoxyguanosine (8-OHdG)) and DNA damage. To our knowledge, such an interaction has never been reported before.

\section{Material and Methods}

\subsection{Particles}

$\mathrm{CeO}_{2} \mathrm{NPs}, 10 \mathrm{wt}$. \% in water with an average diameter of $20 \mathrm{~nm}$, were obtained from Sigma-Aldrich (St Louis, MO, USA). $\mathrm{CeO}_{2} \mathrm{NPs}$ samples diluted in saline were used for rat exposures. To minimize aggregation, particle suspensions were always sonicated for $5 \mathrm{~min}$ (Clifton Ultrasonic Bath, Clifton, NJ, USA). Particle suspensions were prepared promptly before use and were vortexed to obtain well mixed suspension prior to each instillation. The same particles from the same source were characterized and used recently by Ma et al. and by us [8,15-17].

The endotoxin concentration in the $\mathrm{CeO}_{2}$ NPs and saline used was quantified, as described by the manufacturer, by chromogenic Limulus Amebocyte Lysate (Pierce, Rockford, IL, USA) test. The concentrations were lower than the detection limit $(0.1 \mathrm{EU} / \mathrm{mL})$ in the saline and $\mathrm{CeO}_{2} \mathrm{NPs}$ solutions. 


\subsection{Animals and i.t. Instillation}

This project was reviewed and approved by the Institutional Review Board of the United Arab Emirates University (ERA_2016_4408,17/11/2016), and experiments were performed in accordance with protocols approved by the Institutional Animal Care and Research Advisory Committee.

A total number of 76 male Wistar rats (Taconic Farms Inc., Germantown, New York, USA) were used in this study. Rats were aged 10-12 weeks and, initially weighing $223 \pm 13$ g, were given a standard laboratory chow and water ad libitum. They were randomly divided into four groups and individually housed at a temperature of $23 \pm 2{ }^{\circ} \mathrm{C}$, relative humidity of $50-60 \%$ and a $12 \mathrm{~h}$ dark-light cycle. The rats were weighed at the beginning of the experiment and just before sacrifice. Rats were cared for under a protocol approved by the Animal Research Ethics Committee of our college, and according to the NIH Guide for the Care and Use of Laboratory Animals, NIH publication no. 85-23, 1985.

\subsection{Treatments}

Vascular toxicity in rats was induced by a single intraperitoneal (i.p.) injection of CP (David Bull Laboratories, PTY Ltd., Victoria, Australia) at a dose of $6 \mathrm{mg} / \mathrm{kg}[18,19]$. Control animals received a similar volume of normal saline i.p. On day 6 of treatment, the animals were anaesthetized by isoflurane inhalation, and placed supine with extended neck on an angled board. A Becton Dickinson 18 Gauge cannula was inserted via the mouth into the trachea. $\mathrm{CeO}_{2} \mathrm{NPs}$ suspension $(150 \mu \mathrm{L})$ or saline-only were instilled $(150 \mu \mathrm{L})$ via a sterile syringe and followed by an air bolus of $100 \mu \mathrm{L}$. The dose of the $\mathrm{CeO}_{2}$ NPs was selected based on previous work [17].

The four groups were treated as follows:

Group 1: single normal saline (control, $500 \mu \mathrm{L} / \mathrm{rat}$ ) given i.p., and on day 6 of the treatment, a single i.t. administration of saline $(150 \mu \mathrm{L}$ per rat);

Group 2: single normal saline (control, $500 \mu \mathrm{L} / \mathrm{rat}$ ) given i.p., and on day 6 of the treatment, a single i.t. administration of $\mathrm{CeO}_{2} \mathrm{NPs}(1 \mathrm{mg} / \mathrm{kg})$;

Group 3: single $\mathrm{CP}(6 \mathrm{mg} / \mathrm{kg})$ given i.p., and on day 6 of the treatment, a single i.t. administration of saline $(150 \mu \mathrm{L}$ per rat);

Group 4: single CP $(6 \mathrm{mg} / \mathrm{kg})$ given i.p., and on day 6 of the treatment, a single i.t. administration of $\mathrm{CeO}_{2} \mathrm{NPs}(1 \mathrm{mg} / \mathrm{kg})$;

Twenty-four hours after the i.t. instillation of $\mathrm{CeO}_{2} \mathrm{NPs}$ or saline with or without $\mathrm{CP}$ treatment, various biochemical and histological endpoints were measured in the aortae of rats.

\subsection{Sample Collection and Biochemical Analysis}

For the biochemical analysis a sample size of 32 rats was used. The animals were sacrificed with an overdose of anaesthesia. The chest was opened and the thoracic aorta (arch to bifurcation) was quickly removed and kept in a $4{ }^{\circ} \mathrm{C} \mathrm{PBS}$ (pH 7.4), and blood, connective tissue, and fat were removed from each vessel, and the aorta was cut into rings of 3-4 $\mathrm{mm}$ in length, weighed and subjected to homogenization for biochemical studies [8,20,21].

The aortic homogenates were prepared as described previously $[8,21,22]$. Homogenates were centrifuged for $10 \mathrm{~min}$ at $3000 \times \mathrm{g}$ to remove cellular debris, and the supernatants were used for further analysis [21]. Protein content was measured by Bradford's method. The NADPH-dependent membrane LPO was determined using a kit that measures thiobarbituric acid reactive substances (Cayman Chemical Company, Ann Arbor, MI, USA). GSH was measured with a kit obtained from Sigma-Aldrich Co (St Louis, MO, USA). The measurement of CAT and SOD activities was performed using kits from Cayman Chemical Company (Ann Arbor, MI, USA). The determination of NO was achieved with a total NO assay kit from R\&D systems (Minneapolis, MN, USA) which measures the more stable $\mathrm{NO}$ metabolites $\mathrm{NO}_{2}{ }^{-}$and $\mathrm{NO}_{3}{ }^{-}$[23]. The aortic homogenate concentration of 8-OH-dG was quantified using an ELISA kit (Cayman, Ann Arbor, MI, USA) according to the manufacturer's instructions. The concentrations of TNF $\alpha$ and IL- 6 were determined using commercial Kits (Duo 
Set, R \& D systems, Minneapolis, MN, USA). The number of animals per group was 8 . Thus, for the majority of the biochemical parameters measured, we used $n=8$, and in a few of them we used $n=5-7$ (see figure legends). This was due to the volume of homogenate recovered from aortic tissues which was slightly variable. The latter depended on the animal weight and the weight of the aortic tissues collected. We were also limited by the amount of reagents available for some biochemical tests (total $\mathrm{NO}$ and 8-OH-dG), which allowed us to run $n=5-6$.

\subsection{Histology and Immunohistochemistry}

For histological and immunohistochemistry analysis, a sample size of 24 rats ( $n=6$ per group) was used. Segments of aorta collected as described above were cassetted and fixed directly in $10 \%$ neutral formalin for $24 \mathrm{~h}$, which was followed by dehydration in increasing concentrations of ethanol, clearing with xylene and embedding with paraffin. Three- $\mu \mathrm{m}$ sections were prepared from paraffin blocks and stained with haematoxylin and eosin. The stained sections were evaluated by the histopathologist (S.A.), using light microscopy.

Regarding immunohistochemistry, five- $\mu \mathrm{m}$ sections were cut, de-waxed with xylene and rehydrated with graded alcohol. The slides were then placed in a $0.01 \mathrm{M}$ citrate buffer solution $(\mathrm{pH}=6.0)$ and pre-treatment procedures to unmask the antigens were performed in a water bath for $60 \mathrm{~min}$. Sections were treated with peroxidase and protein block for $15 \mathrm{~min}$ each and then incubated with the primary antibodies anti-Nrf2 (rabbit polyclonal antibody, Abcam, Cambridge, UK) for one hour at room temperature. After conjugation with primary antibody, sections were washed and then incubated with Dako REAL ${ }^{\mathrm{TM}}$ EnVision $^{\mathrm{TM}} / \mathrm{HRP}$ for $1 \mathrm{~h}$ at room temperature (DAKO, Agilent, CA, USA), followed by washing and addition of DAB chromogen (DAKO, Agilent, Santa Clara, CA, USA). Sections were then counter stained with haematoxylin. Appropriate positive controls were used. For the negative control, the primary antibody was not added to sections and the whole procedure was carried out in the same manner as mentioned above. The immunohistochemical staining for Nrf2 was scored semi-quantitatively and blindly by our histopathologist on a scale of $0-4$ according to the percentage of staining in 4 slides of each specimen, and each slide contained 4 equal coronal segments of the aorta. A score of 0 was assigned if the expression was $0-10 \%, 1$ for $11-25 \%, 2$ for $26-50 \%, 3$ for $51-75 \%$ and 4 for more than $75 \%$ [24,25]. The number of nuclei of smooth muscles and endocardial cells stained with Nrf2 were counted at high power field $(\times 100)$ [26].

\subsection{Assessment of DNA Damage by COMET Assay}

In separate sets of animals ( $n=20$, i.e., $n=5$ per group), immediately after sacrifice, the aortae were removed from each animal as described above. Single-cell suspensions of the different aortae were obtained and analysed according to the method described in our previous publications [27-30]. Each aorta was washed in a chilled medium (RPMI 1640, 15\% DMSO, 1.8\% (w/v) NaCl). The aortic tissues were put in $1.5 \mathrm{~mL}$ medium and cut finely into pieces in a Petri dish. The slices were allowed to deposit, and the supernatant was collected in a $15 \mathrm{~mL}$ tube. The collected cell suspension was centrifuged at $1000 \mathrm{rpm}$ for $5 \mathrm{~min}$ at $4{ }^{\circ} \mathrm{C}$. The supernatant was removed, and the pellets were suspended in $0.5 \mathrm{~mL}$ of the medium. The rest of the procedure performed was as described earlier [27-30].

\subsection{Statistics}

All data were analysed with GraphPad Prism Version 4.01 for Windows software (Graphpad Software Inc., San Diego, CA, USA). Data were analysed for normal distribution using the D'Agostino and Pearson omnibus normality test. Data are expressed as means \pm SEM. Comparisons between groups were performed by one-way analysis of variance (ANOVA), followed by Newman Keuls test for comparing treated with control groups. P values $<0.05$ are considered significant. 


\section{Results}

\subsection{GSH Concentration and CAT and SOD Activities in Aortic Homogenates}

The quantification of the concentration of the free radical scavenger GSH and the activities of the antioxidant enzymes SOD, and CAT following pulmonary exposure to either saline or $\mathrm{CeO}_{2} \mathrm{NPs}$ with or without $\mathrm{CP}$ administration are shown in Figure 1. Figure 1A shows that the concentration of GSH was significantly increased in $\mathrm{CP}+$ saline versus saline group $(P<0.01)$, and in $\mathrm{CP}+\mathrm{CeO}_{2} \mathrm{NPs}$ compared with either with either $\mathrm{CP}+$ saline $(P<0.001)$ or $\mathrm{CeO}_{2} \mathrm{NPs}(P<0.0001)$ group. Figure $1 \mathrm{~B}$ displays that the activity of CAT was significantly increased in $\mathrm{CP}+$ saline versus saline group $(P<0.0001)$, and in $\mathrm{CP}+\mathrm{CeO}_{2} \mathrm{NPs}$ compared with either with either $\mathrm{CP}+$ saline $(P<0.05)$ or $\mathrm{CeO}_{2} \mathrm{NPs}(P<0.0001)$ group. Furthermore, Figure $1 C$ shows that the activity of SOD was significantly decreased in $\mathrm{CP}+$ saline versus saline group $(P<0.0001)$, in $\mathrm{CeO}_{2} \mathrm{NPs}$ versus saline group $(P<0.0001)$, and in $\mathrm{CP}+\mathrm{CeO}_{2} \mathrm{NPs}$ compared with either with either $\mathrm{CP}+$ saline $(P<0.05)$ or $\mathrm{CeO}_{2} \mathrm{NPs}(P<0.05)$ group.

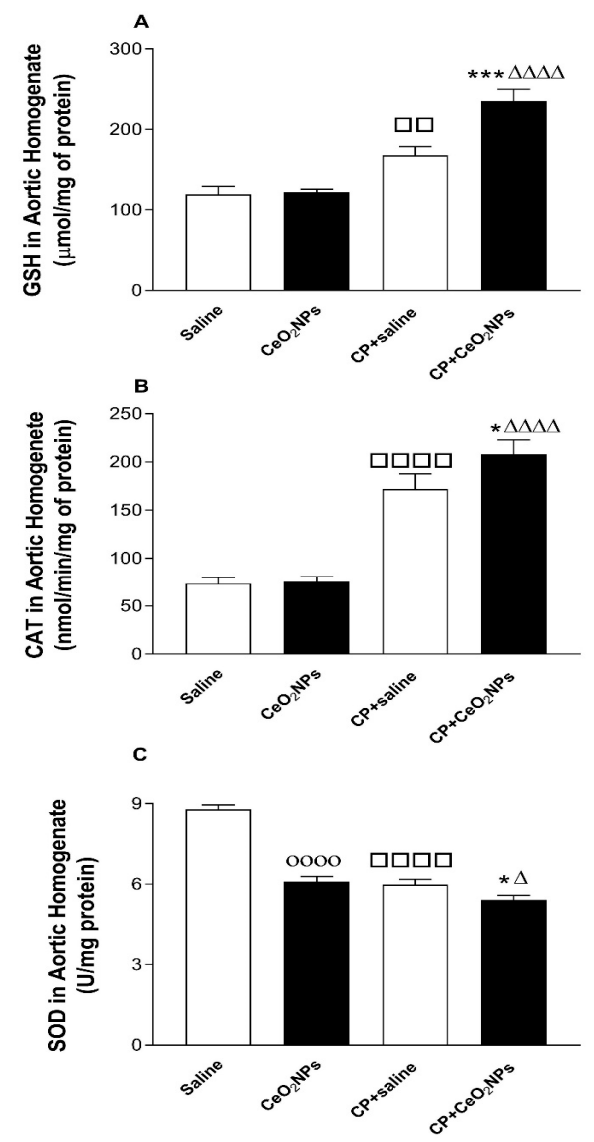

Figure 1. Glutathione (GSH, (A)) concentration in aortic homogenates of rats intratracheally instilled with either saline $(n=8)$ or $\mathrm{CeO}_{2} \mathrm{NPs}(n=8)$ with $(n=8)$ or without $(n=8) \mathrm{CP}$ administration. *** $P<0.001$ compared with $\mathrm{CP}+$ saline-treated group. ${ }^{\Delta \Delta \Delta \Delta} P<0.0001$ compared with $\mathrm{CeO}_{2}$ NPs-treated group. ${ }^{\square} P<0.01$ compared with saline-treated group. Catalase (CAT, (B)) activity in aortic homogenates of rats intratracheally instilled with either saline $(n=8)$ or $\mathrm{CeO}_{2} \mathrm{NPs}(n=8)$ with $(n=6)$ or without $(n=6) \mathrm{CP}$ administration. ${ }^{*} P<0.05$ compared with $\mathrm{CP}+$ saline-treated group. ${ }^{\Delta \Delta \Delta \Delta} P<0.0001$ compared with $\mathrm{CeO}_{2}$ NPs-treated group. ${ }^{\square} \mathrm{Cu} P<0.0001$ compared with the saline-treated group. Superoxide dismutase (SOD, $(C))$ activity in aortic homogenates of rats intratracheally instilled with either saline $(n=8)$ or $\mathrm{CeO}_{2} \mathrm{NPs}(n=8)$ with $(n=8)$ or without $(n=8) \mathrm{CP}$ administration. ${ }^{*} P<0.05$ compared with the $\mathrm{CP}+$ saline-treated group. ${ }^{\Delta} P<0.05$ compared with the $\mathrm{CeO}_{2}$ NPs-treated group. ${ }^{\square} \mathrm{a} \square<0.0001$ compared with the saline-treated group. ${ }^{\text {oooo }} P<0.0001$ compared with the saline-treated group. Data are mean \pm SEM. 


\subsection{Histopathological Analysis of the Aorta and Expression of Nrf2}

Figure 2 suggests that there were no significant light-microscopic differences in the H\&E-stained aortic sections between the four groups studied (saline, $\mathrm{CeO}_{2} \mathrm{NPs}, \mathrm{CP}+$ saline and $\mathrm{CP}+\mathrm{CeO}_{2} \mathrm{NPs}$ groups).

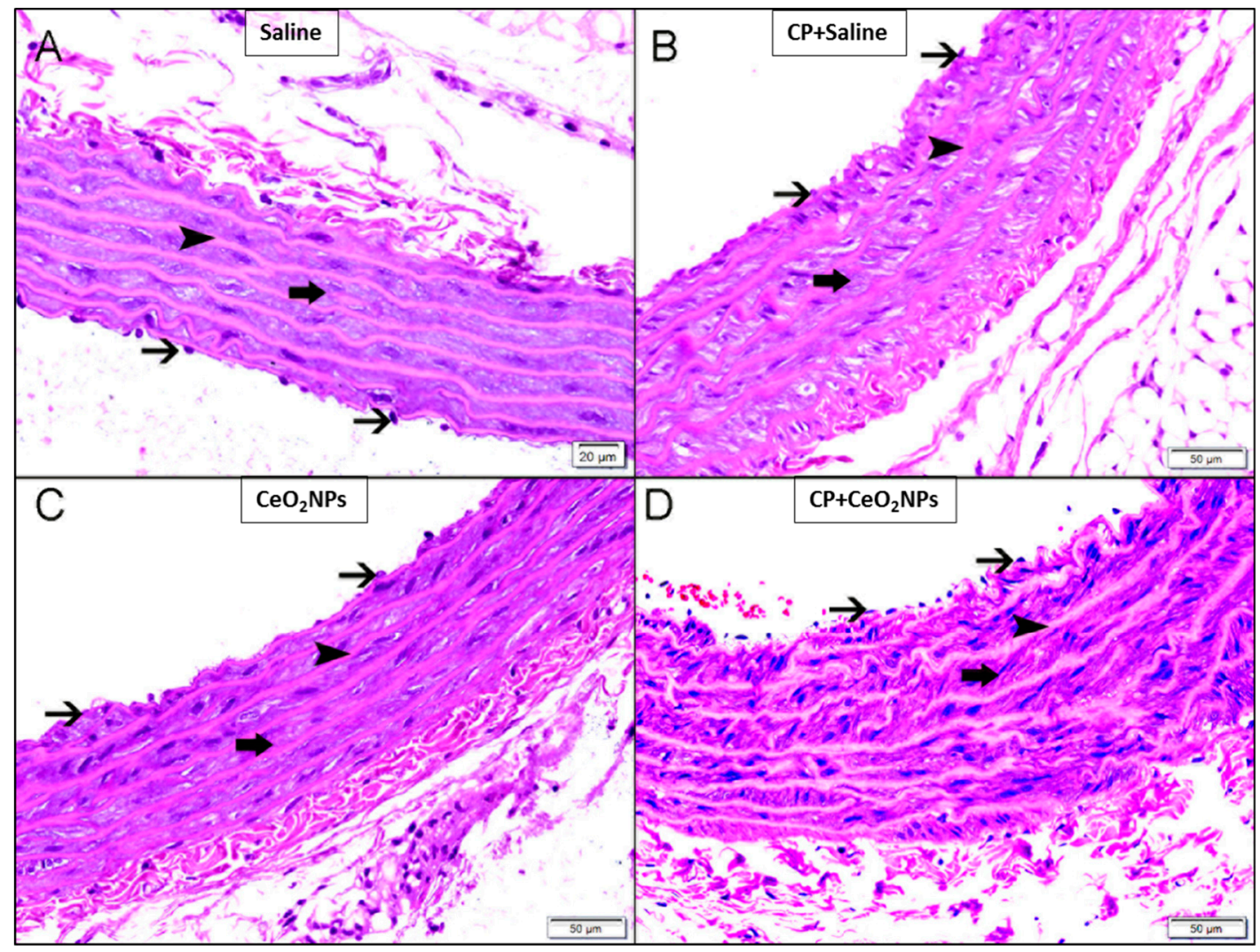

Figure 2. (A-D) Representative light microscopy sections of $\mathrm{H}$ and E-stained aortic tissues of rats intratracheally instilled with either saline (control) or cerium oxide nanoparticles $\left(\mathrm{CeO}_{2} \mathrm{NPs}\right)$ with or without cisplatin (CP) administration. (A) Representative aortic section obtained from saline-treated rats displaying normal aorta with unremarkable changes showing endocardial cells lining (thin arrow), elastic fibres (arrowhead) and smooth muscles (thick arrow). (B) Representative aortic section obtained from rats treated with $\mathrm{CP}$ and intratracheally instilled with saline with unremarkable changes showing endocardial cells lining (thin arrow), elastic fibres (arrowhead) and smooth muscles (thick arrow). (C) Representative aortic section obtained from $\mathrm{CeO}_{2} \mathrm{NPs}$-treated rats displaying normal aorta with unremarkable changes showing endocardial cells lining (thin arrow), elastic fibres (arrowhead) and smooth muscles (thick arrow). (D) Representative aortic section obtained from rats treated with CP and intratracheally instilled with $\mathrm{CeO}_{2}$ NPs with unremarkable changes showing endocardial cells lining (thin arrow), elastic fibres (arrowhead) and smooth muscles (thick arrow).

At the time point investigated, the study of Nrf2 expression, a transcription factor which plays an important role in the instigation of antioxidant enzymes to respond to oxidative stress, in aorta of saline-instilled control rats showed normal aorta with Nrf2 nuclear staining of a few endocardial cells and smooth muscles (Figure 3A,E). The number of nuclei of smooth muscles and endocardial cells stained with Nrf2 in CP + saline group (Figure 3B,E) was significantly elevated compared with that in the saline group (Figure 3A,E). Likewise, the numbers of nuclei of smooth muscles and endocardial cells stained with $\mathrm{Nrf} 2$ in $\mathrm{CeO}_{2} \mathrm{NPs}$ (Figure $3 \mathrm{C}$,E) were significantly increased compared with the saline group (Figure $3 \mathrm{~A}, \mathrm{E}$ ). Moreover, the concomitant administration of $\mathrm{CP}$ and $\mathrm{CeO}_{2} \mathrm{NPs}$ (Figure 3D,E) 
further increased the number of nuclei of smooth muscles and endocardial cells stained with Nrf2 compared with $\mathrm{CeO}_{2} \mathrm{NPs}$ group (Figure 3C,E).
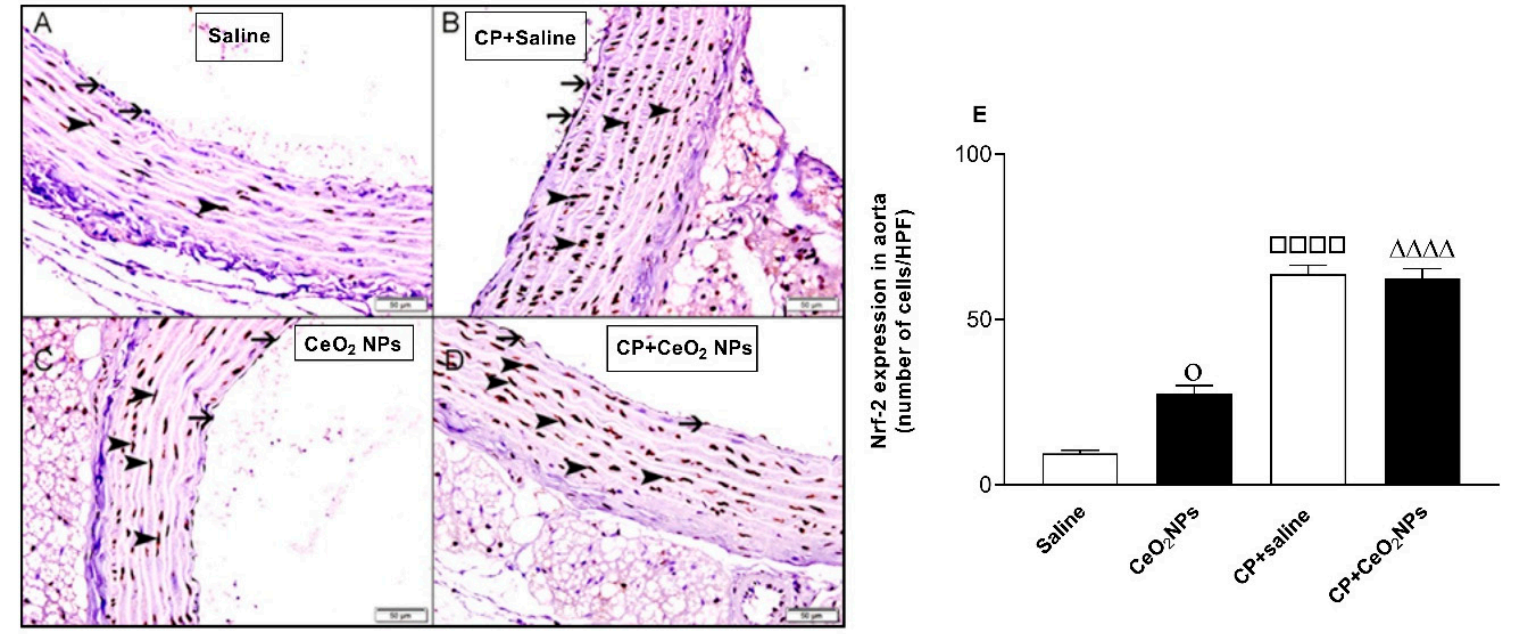

Figure 3. (A-E): Immunohistochemical analysis of the aortic tissue sections for the detection of nuclear factor erythroid-derived 2-like 2 (Nrf2) in rats intratracheally instilled with either saline (control) or cerium oxide nanoparticles $\left(\mathrm{CeO}_{2} \mathrm{NPs}\right)$ with or without cisplatin (CP) administration. (A) Representative section of the aorta of saline-treated rats showing normal aorta with nuclear staining of a few endocardial cells and smooth muscles with Nrf2. (B) Representative section of the aorta of rats treated with $\mathrm{CP}$ and intratracheally instilled with saline showing increased number of nuclei of smooth muscles and endocardial cells stained with Nrf2. (C) Representative section of the aorta of $\mathrm{CeO}_{2}$ NPs-treated rats showing increased number of nuclei of smooth muscles and endocardial cells stained with Nrf2. (D) Representative section of the aorta of rats treated with CP and intratracheally instilled with $\mathrm{CeO}_{2}$ NPs showing increased number of nuclei of smooth muscles and endocardial cells stained with Nrf2. (E) Quantification of the numbers of nuclei of smooth muscles and endocardial cells stained with Nrf2 per high power field (HPF) in rats intratracheally instilled with either saline $(n=6)$ or $\mathrm{CeO}_{2} \mathrm{NPs}(n=6)$ with $(n=6)$ or without $(n=6) \mathrm{CP}$ administration. ${ }^{\Delta \Delta \Delta \Delta} P<0.0001$ compared with $\mathrm{CeO}_{2}$ NPs-treated group. ${ }^{\square 0 \square} P<0.0001$ compared with saline-treated group. ${ }^{\circ} P<0.05$ compared with saline-treated group. Data are mean \pm SEM.

\subsection{Total NO Concentration in Aortic Homogenates}

The concentration of total NO in aortic homogenates was significantly increased $24 \mathrm{~h}$ after i.t. installation of $\mathrm{CeO}_{2} \mathrm{NPs}$ compared with saline $(P<0.05)$, and in $\mathrm{CP}+$ saline versus saline $(P<0.001)$. Moreover, the total NO concentration was significantly elevated by the combination of $\mathrm{CP}$ and $\mathrm{CeO}_{2}$ NPs compared with both $\mathrm{CP}+$ saline $(P<0.0001)$ and $\mathrm{CeO}_{2} \mathrm{NPs}(P<0.0001)$ groups (Figure 4$)$. 


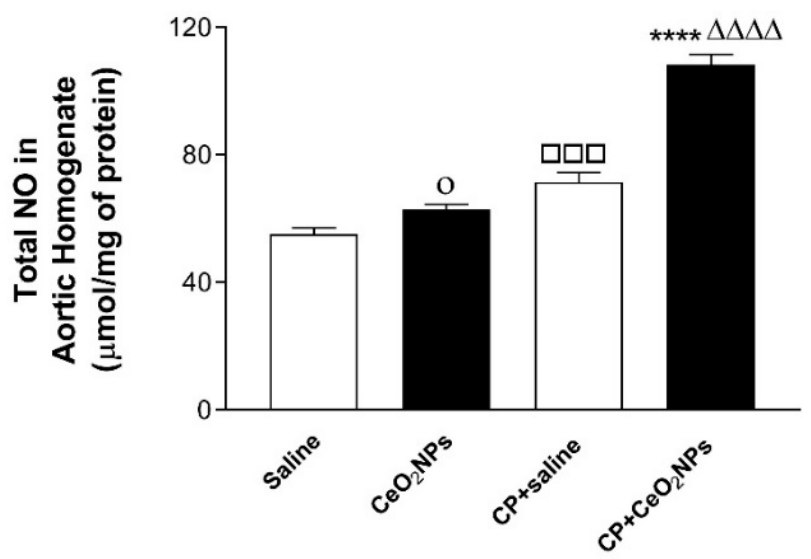

Figure 4. Total nitric oxide (NO) concentration in aortic homogenates of rats intratracheally instilled with either saline $(n=5)$ or $\mathrm{CeO} 2 \mathrm{NPs}(n=5)$ with $(n=5)$ or without $(n=5) \mathrm{CP}$ administration. **** $P<0.0001$ compared with $\mathrm{CP}+$ saline-treated group. ${ }^{\Delta \Delta \Delta \Delta} P<0.0001$ compared with $\mathrm{CeO}_{2}$ NPs-treated group. ${ }^{\square \square} P<0.001$ compared with saline-treated group. ${ }^{\circ} P<0.05$ compared with saline-treated group. Data are mean \pm SEM.

\subsection{LPO Concentrations in Aortic Homogenates}

The concentration of LPO, a marker of lipid peroxidation, following pulmonary exposure to either saline or $\mathrm{CeO}_{2} \mathrm{NPs}$ with or without $\mathrm{CP}$ administration are shown in Figure 5. At the time point investigated, the concomitant treatment with $\mathrm{CP}$ and $\mathrm{CeO}_{2} \mathrm{NPs}$ induced a significant increase in the concentration of LPO in aortic homogenates compared with both $\mathrm{CP}+$ saline $(P<0.001)$ and $\mathrm{CeO}_{2}$ NPs $(P<0.01)$ groups.

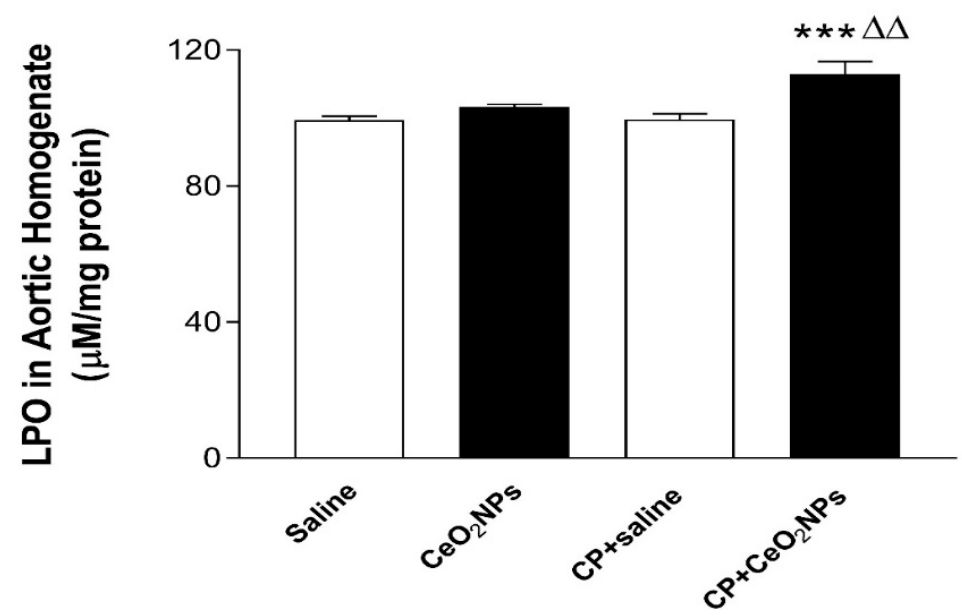

Figure 5. Aortic homogenates concentration of lipid peroxidation (LPO) in rats intratracheally instilled with either saline (control, $n=8)$ or cerium oxide nanoparticles $\left(\mathrm{CeO}_{2} \mathrm{NPs}, n=7\right)$ with $(n=8)$ or without $(n=7)$ cisplatin $(\mathrm{CP})$ administration. ${ }^{* * *} P<0.001$ compared with $\mathrm{CP}+$ saline-treated group. ${ }^{\Delta \Delta} P<0.01$ compared with $\mathrm{CeO}_{2}$ NPs-treated group. Data are mean $\pm \mathrm{SEM}$.

\subsection{8-OH-dG Concentrations in Aortic Homogenates}

The concentration of 8-OH-dG, a marker of oxidative DNA damage, in aortic homogenates was significantly increased $24 \mathrm{~h}$ following pulmonary administration to $\mathrm{CeO}_{2} \mathrm{NPs}$ compared with saline group $(P<0.0001)$, and in $C P+$ saline versus saline $(P<0.0001)$. Moreover, the concentration of 8-OH-dG was significantly increased by the combination of $\mathrm{CP}$ and $\mathrm{CeO}_{2} \mathrm{NPs}$ compared with both $\mathrm{CP}$ + saline $(P<0.05)$ and $\mathrm{CeO}_{2} \mathrm{NPs}(P<0.001)$ groups (Figure 6$)$. 


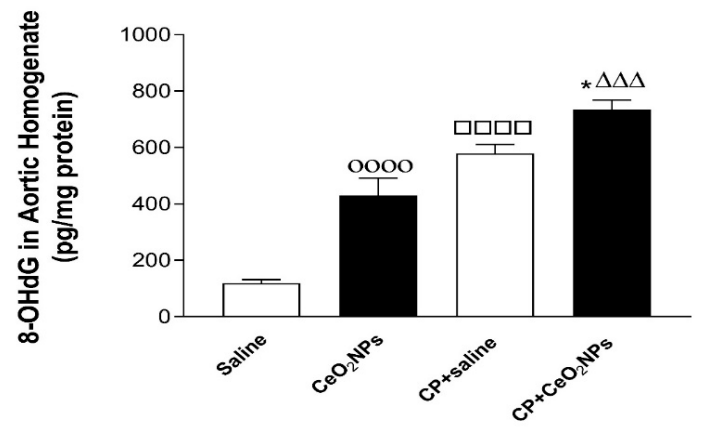

Figure 6. Aortic homogenates concentration of 8-hydroxy-2-deoxyguanosine (8-OH-dG) in rats intratracheally instilled with either saline $(n=6)$ or CeO2 NPs $(n=6)$ with $(n=5)$ or without $(n=6)$ $\mathrm{CP}$ administration. ${ }^{*} P<0.05$ compared with $\mathrm{CP}+$ saline-treated group. ${ }^{\Delta \Delta \Delta} P<0.001$ compared with $\mathrm{CeO}_{2}$ NPs-treated group. ${ }^{\square \square \square} P<0.0001$ compared with saline-treated group. ${ }^{\text {oooo }} P<0.0001$ compared with saline-treated group. Data are mean \pm SEM.

\subsection{IL-6 and TNF $\alpha$ Concentrations in Aortic Homogenates}

Figure 7 illustrates the effects of pulmonary exposure to either saline or $\mathrm{CeO}_{2} \mathrm{NPs}$ with or without $\mathrm{CP}$ administration on the aortic homogenate concentrations of proinflammatory cytokines, IL- 6 and $\mathrm{TNF} \alpha$. Figure 7A shows that, at the time point assessed, the concentration of IL- 6 was significantly increased in $\mathrm{CP}+$ saline group compared with saline group $(P<0.05)$, and in $\mathrm{CP}+\mathrm{CeO}_{2} \mathrm{NPs}$ compared with either $\mathrm{CP}+$ saline $(P<0.01)$ or $\mathrm{CeO}_{2} \mathrm{NPs}(P<0.0001)$ group. Similarly, as depicted in Figure 7B, the concentration of TNF $\alpha$ in aortic homogenates was significantly augmented in $\mathrm{CP}+$ saline group compared with saline group $(P<0.01)$, and in $\mathrm{CP}+\mathrm{CeO}_{2} \mathrm{NPs}$ compared with either $\mathrm{CP}+$ saline $(P<0.001)$ or $\mathrm{CeO}_{2} \mathrm{NPs}(P<0.0001)$ group.
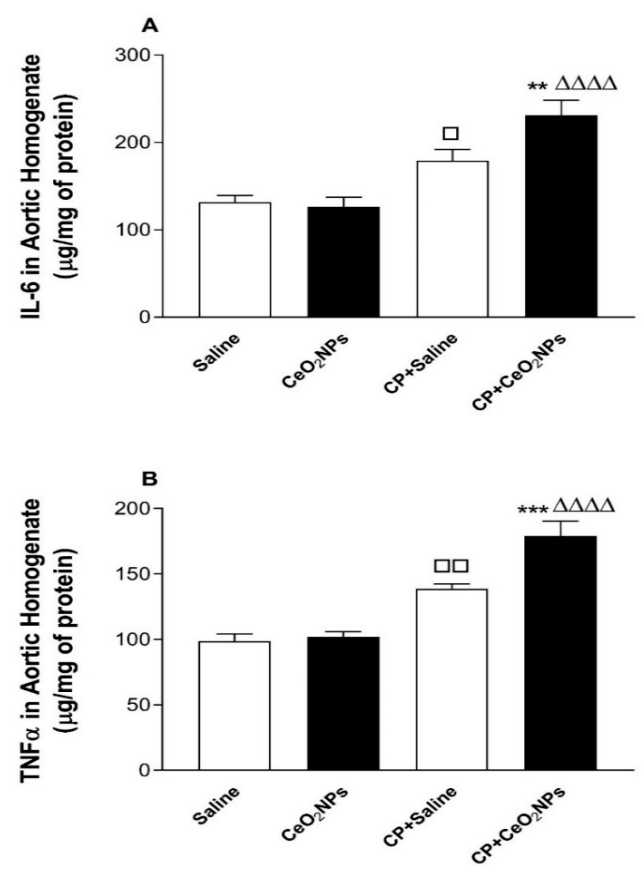

Figure 7. Aortic homogenates concentration of interleukin-6 (IL-6, (A)) in rats intratracheally instilled with either saline (control, $n=8)$ or cerium oxide nanoparticles $\left(\mathrm{CeO}_{2} \mathrm{NPs}, n=8\right)$ with $(n=8)$ or without $(n=8)$ cisplatin $(\mathrm{CP})$ administration. Tumour necrosis factor- $\alpha(\mathrm{TNF} \alpha,(\mathbf{B}))$ concentration in aortic homogenates of rats intratracheally instilled with either saline $(\mathrm{n}=8)$ or $\mathrm{CeO}_{2} \mathrm{NPs}(n=8)$ with $(n=8)$ or without $(n=8) \mathrm{CP}$ administration. ${ }^{* *} P<0.01$ and ${ }^{* * *} P<0.001$ compared with CP + saline-treated group. ${ }^{\Delta \Delta \Delta \Delta} P<0.0001$ compared with $\mathrm{CeO}_{2}$ NPs-treated group. ${ }^{\square} P<0.05$ and ${ }_{\square} P<0.01$ compared with saline-treated group. Data are mean \pm SEM. 


\subsection{Aortic DNA Damage}

Figure 8 depicts the effect of treatments on the aortic DNA damage assessed by the Comet assay. Compared with saline-exposed group, $24 \mathrm{~h}$ following lung exposure to $\mathrm{CeO}_{2} \mathrm{NPs}$, there was a significant augmentation in aortic DNA injury $(P<0.001)$. Likewise, the latter was significantly increased in the $\mathrm{CP}+$ saline group compared with the saline group $(P<0.01)$. Furthermore, the degree of aortic DNA damage was further elevated in the $\mathrm{CP}+\mathrm{CeO}_{2} \mathrm{NPs}$ group compared with either $\mathrm{CP}+$ saline $(P<0.001)$ or $\mathrm{CeO}_{2} \mathrm{NPs}$ alone $(P<0.05)$.

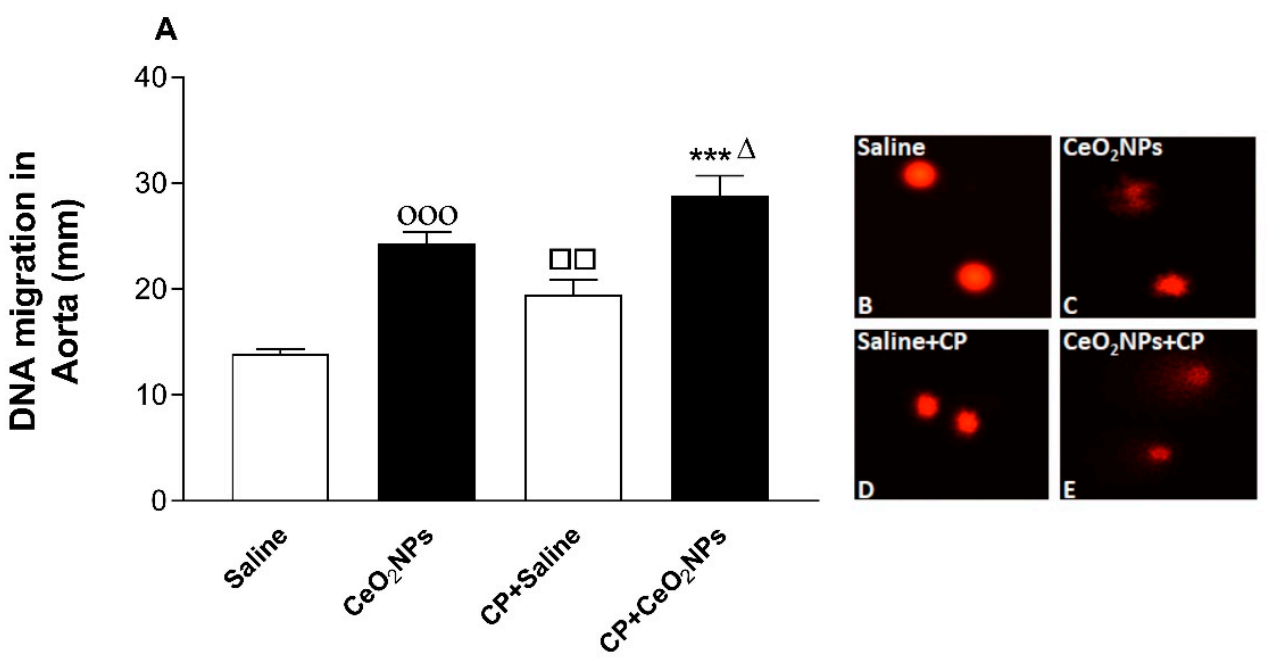

Figure 8. DNA migration ( $\mathrm{mm}$ ) in the aortic tissues evaluated by Comet assay in rats intratracheally instilled with either saline (control, $n=5)$ or cerium oxide nanoparticles $\left(\mathrm{CeO}_{2} \mathrm{NPs}, n=5\right)$ with $(n=5)$ or without $(n=5)$ cisplatin $(\mathrm{CP})$ administration. ${ }^{* *} P<0.001$ compared with $\mathrm{CP}+$ saline-treated group. ${ }^{\Delta} P<0.05$ compared with $\mathrm{CeO}_{2}$ NPs-treated group. ${ }^{\square} \square P<0.01$ compared with saline-treated group. ${ }^{\text {ooo }} P<0.001$ compared with saline-treated group. Data are mean $\pm \mathrm{SEM}$. Images illustrating the quantification of DNA migration by the Comet assay under alkaline conditions in saline, $\mathrm{CeO}_{2} \mathrm{NPs}$ with or without $\mathrm{CP}$ administration.

\section{Discussion}

In this study, we provide experimental evidence that the vascular pathophysiological effects of pulmonary exposure to $\mathrm{CeO}_{2} \mathrm{NPs}$ are potentiated in a rat model of vascular injury. Our study demonstrates that the combination of $\mathrm{CP}$ and $\mathrm{CeO}_{2} \mathrm{NPs}$ exacerbates the aortic oxidative stress, Nrf2 expression, inflammation and DNA damage.

It has been demonstrated that inhalation of $\mathrm{CeO}_{2} \mathrm{NPs}$ causes lung toxicity, crosses the air-blood barrier, and reaches extrapulmonary organs [9]. We have previously reported that i.t. instillation of $\mathrm{CeO}_{2} \mathrm{NPs}$ in mice induces thrombotic complications and causes toxicity in various organs [8,31]. Moreover, it has been reported that pulmonary exposure to $\mathrm{CeO}_{2} \mathrm{NPs}$ causes vascular dysfunction and induces exacerbation of myocardial ischemia/reperfusion injury in mice [32]. It is well-established that the use of the anti-cancer drug $\mathrm{CP}$ is associated with several adverse effects, especially nephrotoxicity and vascular injury, and hence it is widely used experimentally in rats to induce kidney, cardiac and vascular injury $[12-14,17,20]$. However, as far as we are aware, no study has investigated systematically the oxidative stress, Nrf2 expression, inflammation and DNA damage in aortic tissue of rats treated $\mathrm{CP}$ to induce vascular injury and i.t. instilled with $\mathrm{CeO}_{2} \mathrm{NPs}$. The i.t. instillation technique used in the present study is simpler than inhalation, thus permitting the administration of a range of doses to the lung in a short-time [1,3,4]. Additionally, the latter technique delivers more accurate dosing, taking into consideration that rats are nose breathers that filter most inhaled particles $[1,3,4]$ The experimental approach used here consisting of assessing the effects of pulmonary exposure to $\mathrm{CeO}_{2}$ NPs in a rat model of vascular injury induced by $\mathrm{CP}$ is relevant because it is well-established 
that patients with compromised vascular homeostasis have increased susceptibility to the effects of particulate air pollution $[3,10,11]$. We have recently demonstrated that the presence of $\mathrm{CeO}_{2} \mathrm{NPs}$ $(1 \mathrm{mg} / \mathrm{kg})$ in the lung exacerbated the renal and lung effects of CP-induced nephrotoxicity in rats [17]. In this study, we used the same dose of $\mathrm{CeO}_{2} \mathrm{NPs}$ and experimental protocol, and focused our work on the mechanism of action in the aortic tissue. Oxidative stress has been acknowledged as playing a key role in the development of vascular damage [33]. Here we measured in aortic homogenates GSH, a free radical scavenger, and two major antioxidant enzymes, namely CAT and SOD. Our data show that the concentrations of GSH and the activity of CAT were augmented in rats administered with $\mathrm{CeO}_{2} \mathrm{NPs}$ and CP compared with either $\mathrm{CP}+$ saline or $\mathrm{CeO}_{2} \mathrm{NPs}$. The augmentation of GSH and CAT suggests that the increase in oxidative stress was associated with an elevation of antioxidant capacity, indicating the occurrence of an adaptive responses that counterweight the potentially detrimental activity of oxygen radicals and reducing further oxidant-mediated aortic damage [8,26]. On the other hand, we found that SOD activity was significantly reduced in $\mathrm{CeO}_{2} \mathrm{NPs}+\mathrm{CP}$ compared with both $\mathrm{CP}+$ saline and $\mathrm{CeO} 2 \mathrm{NPs}$, suggesting a consumption of this antioxidant during the breakdown of free radicals $[8,26]$. Nrf2 is a transcription factor which is triggered by reactive oxygen species in the vasculature causing the upregulation of several antioxidant genes [34,35]. Proatherogenic conditions induced by metabolic diseases or cigarette smoking have been shown to increase the production of reactive oxygen species in arteries which in turn trigger adaptive mechanisms involving the induction of Nrf2 [34,35]. Here, we show that the expression of Nrf2 by the nuclei of smooth muscles and endocardial cells was significantly augmented in $\mathrm{CeO}_{2} \mathrm{NPs}$ versus saline and in $\mathrm{CP}+$ saline versus saline. Moreover, Nrf2 expression was significantly increased in $\mathrm{CP}+\mathrm{CeO}_{2} \mathrm{NPs}$ versus $\mathrm{CeO}_{2} \mathrm{NPs}$. However, unlike the measured antioxidants which were potentiated in $\mathrm{CP}+\mathrm{CeO}_{2} \mathrm{NPs}$ versus $\mathrm{CP}+$ saline, the levels of Nrf2 expression in the aorta was comparable in these two groups. The reason for this finding is uncertain, and additional work is required to clarify this point. Moreover, in the present study, we assessed the total NO; LPO, which is a marker of lipid peroxidation; and 8-OH-dG, a marker of oxidative stress to DNA. Our data show a significant elevation of the total NO in aortic homogenates of rats exposed to $\mathrm{CeO}_{2} \mathrm{NPs}$ and $\mathrm{CP}$ compared with both $\mathrm{CP}+$ saline and $\mathrm{CeO}_{2} \mathrm{NPs}$. Moreover, the concentrations of LPO and 8-OH-dG were significantly increased in rats treated with $\mathrm{CeO}_{2} \mathrm{NPs}_{\text {and }}$ $\mathrm{CP}$ compared with both $\mathrm{CP}+$ saline and $\mathrm{CeO}_{2} \mathrm{NPs}$. The latter findings indicate the occurrence of lipid peroxidation and oxidative DNA damage. Similar to the markers of oxidative stress, the concentrations of the proinflammatory cytokines IL- 6 and TNF $\alpha$ were also significantly potentiated by the combination of $\mathrm{CP}$ and $\mathrm{CeO}_{2} \mathrm{NPs}$ versus either $\mathrm{CP}+$ saline or $\mathrm{CeO}_{2} \mathrm{NPs}$. These results indicate that the aortic inflammation and oxidative stress responses to pulmonary exposure to $\mathrm{CeO}_{2} \mathrm{NPs}$ are aggravated in rats with compromised vascular homeostasis. Inflammation and proxidant-antioxidant disproportion could exert a substantial role in the occurrence and progression of cardiovascular dysfunction [36]. Moreover, it is well-established that the increase of pro-inflammatory cytokines and reactive oxygen species can induce damage of biomolecules, comprising DNA [36]. The occurrence of DNA damage following exposure to $\mathrm{CeO}_{2} \mathrm{NPs}$ has been previously reported in vitro using human skin melanoma cells, human dermal fibroblasts, mouse spermatozoa and oocytes, and in vivo in various organs of mouse after i.t. instillation [8,37-40]. Our data show the occurrence of aortic DNA damage evidenced by COMET assay. In fact, DNA damage in the aorta was significantly increased in $\mathrm{CeO}_{2} \mathrm{NPs}$ compared with saline, and in $\mathrm{CP}+$ saline versus saline, and these effects were significantly aggravated by the combination of $\mathrm{CP}$ and $\mathrm{CeO}_{2}$ NPs. This effect has, as far as we know, not been reported in aorta before. It has been recently demonstrated that the i.t. administration of $\mathrm{CeO}_{2} \mathrm{NPs}$ in $\mathrm{CP}$-treated rats exacerbated DNA damage in the kidney and lung [17].

\section{Conclusions}

We conclude that pulmonary exposure to $\mathrm{CeO}_{2}$ NPs induces impairment of vascular homeostasis in animal model of vascular injury through mechanisms involving oxidative stress, Nrf2 expression, inflammation and DNA damage. Our study illustrates the relevance of performing exhaustive 
assessment of the toxicity of $\mathrm{CeO}_{2} \mathrm{NPs}$ in animal models of human diseases which simulate vulnerable patients with pre-existing vascular diseases.

Author Contributions: All authors have read and approved the manuscript. A.N. designed, planned, supervised all the experiments, and wrote the manuscript. S.A.-S. performed and wrote the histopathological part of the work. S.B. and P.Y. performed the experiments. B.H.A. contributed to the design and the writing of the manuscript.

Funding: This work was supported by funds of the College of Medicine and Health Sciences grant, United Arab Emirates University (UAEU) and by a joint UAEU-SQU grant.

Conflicts of Interest: The authors declare no conflict of interest.

\section{References}

1. Radomska, A.; Leszczyszyn, J.; Radomski, M.W. The Nanopharmacology and Nanotoxicology of Nanomaterials: New Opportunities and Challenges. Adv. Clin. Exp. Med. 2016, 25, 151-162. [CrossRef] [PubMed]

2. Hoet, P.H.M.; Nemmar, A.; Nemery, B. Health impact of nanomaterials? Nat. Biotechnol. 2004, 22, 19. [CrossRef] [PubMed]

3. Nemmar, A.; Holme, J.A.; Rosas, I.; Schwarze, P.E.; Alfaro-Moreno, E. Recent advances in particulate matter and nanoparticle toxicology: A review of the in vivo and in vitro studies. BioMed Res. Int. 2013, 2013, 279371. [CrossRef] [PubMed]

4. Oberdorster, G. Safety assessment for nanotechnology and nanomedicine: Concepts of nanotoxicology. J. Intern. Med. 2010, 267, 89-105. [CrossRef] [PubMed]

5. Cassee, F.R.; van Balen, E.C.; Singh, C.; Green, D.; Muijser, H.; Weinstein, J.; Dreher, K. Exposure, health and ecological effects review of engineered nanoscale cerium and cerium oxide associated with its use as a fuel additive. Crit. Rev. Toxicol. 2011, 41, 213-229. [CrossRef] [PubMed]

6. Selvan, A.M.; Anand, V.; Udayakumar, M.R.B. Effects of cerium oxide nanoparticle addition in diesel and diesel-biodiesel-ethanol blends on the performance and emission characteristics of a CI engine. J. Eng. Appl. Sci. 2009, 4, 1-6.

7. Park, B.; Donaldson, K.; Duffin, R.; Tran, L.; Kelly, F.; Mudway, I.; Morin, J.P.; Guest, R.; Jenkinson, P.; Samaras, Z.; et al. Hazard and risk assessment of a nanoparticulate cerium oxide-based diesel fuel additive-A case study. Inhal. Toxicol. 2008, 20, 547-566. [CrossRef] [PubMed]

8. Nemmar, A.; Yuvaraju, P.; Beegam, S.; Fahim, M.A.; Ali, B.H. Cerium Oxide Nanoparticles in Lung Acutely Induce Oxidative Stress, Inflammation, and DNA Damage in Various Organs of Mice. Oxid. Med. Cell. Longev. 2017, 2017, 9639035. [CrossRef]

9. Snow, S.J.; Mcgee, J.; Miller, D.B.; Bass, V.; Schladweiler, M.C.; Thomas, R.F.; Krantz, T.; King, C.; Ledbetter, A.D.; Richards, J.; et al. Inhaled diesel emissions generated with cerium oxide nanoparticle fuel additive induce adverse pulmonary and systemic effects. Toxicol. Sci. 2014, 142, 403-417. [CrossRef]

10. Wilson, S.J.; Miller, M.R.; Newby, D.E. Effects of Diesel Exhaust on Cardiovascular Function and Oxidative Stress. Antioxid. Redox Signal. 2018, 28, 819-836. [CrossRef]

11. Newby, D.E.; Mannucci, P.M.; Tell, G.S.; Baccarelli, A.A.; Brook, R.D.; Donaldson, K.; Forastiere, F.; Franchini, M.; Franco, O.H.; Graham, I.; et al. Expert position paper on air pollution and cardiovascular disease. Eur. Heart J. 2015, 36, 83-93b. [CrossRef] [PubMed]

12. Mathe, C.; Bohacs, A.; Duffek, L.; Lukacsovits, J.; Komlosi, Z.I.; Szondy, K.; Horvath, I.; Muller, V.; Losonczy, G. Cisplatin nephrotoxicity aggravated by cardiovascular disease and diabetes in lung cancer patients. Eur. Respir. J. 2011, 37, 888-894. [CrossRef] [PubMed]

13. Ali, B.H.; Al-Salam, S.; Al Husseini, I.S.; Al-Lawati, I.; Waly, M.; Yasin, J.; Fahim, M.; Nemmar, A. Abrogation of cisplatin-induced nephrotoxicity by emodin in rats. Fundam. Clin. Pharmacol. 2013, 27, 192-200. [CrossRef] [PubMed]

14. Saleh, R.M.; Awadin, W.F.; El-Shafei, R.A.; Elseady, Y.Y.; Wehaish, F.E.; Elshal, M.F. Cardioprotective role of tadalafil against cisplatin-induced cardiovascular damage in rats. Eur. J. Pharmacol. 2015, 765, 574-581. [CrossRef] [PubMed] 
15. Ma, J.Y.; Zhao, H.; Mercer, R.R.; Barger, M.; Rao, M.; Meighan, T.; Schwegler-Berry, D.; Castranova, V.; Ma, J.K. Cerium oxide nanoparticle-induced pulmonary inflammation and alveolar macrophage functional change in rats. Nanotoxicology 2011, 5, 312-325. [CrossRef] [PubMed]

16. Ma, J.Y.; Young, S.H.; Mercer, R.R.; Barger, M.; Schwegler-Berry, D.; Ma, J.K.; Castranova, V. Interactive effects of cerium oxide and diesel exhaust nanoparticles on inducing pulmonary fibrosis. Toxicol. Appl. Pharmacol. 2014, 278, 135-147. [CrossRef] [PubMed]

17. Nemmar, A.; Al-Salam, S.; Al Ansari, Z.; Alkharas, Z.A.; Al Ahbabi, R.M.; Beegam, S.; Yuvaraju, P.; Yasin, J.; Ali, B.H. Impact of pulmonary exposure to cerium oxide nanoparticles on experimental acute kidney injury. Cell. Physiol. Biochem. 2019, 52, 439-454. [PubMed]

18. Ali, B.H.; Al Moundhri, M.S.; Tag, E.M.; Nemmar, A.; Tanira, M.O. The ameliorative effect of cysteine prodrug L-2-oxothiazolidine-4-carboxylic acid on cisplatin-induced nephrotoxicity in rats. Fundam. Clin. Pharmacol. 2007, 21, 547-553. [CrossRef]

19. Ali, B.H.; Al Moundhri, M.; Eldin, M.T.; Nemmar, A.; Al Siyabi, S.; Annamalai, K. Amelioration of cisplatin-induced nephrotoxicity in rats by tetramethylpyrazine, a major constituent of the Chinese herb Ligusticum wallichi. Exp. Biol. Med. (Maywood) 2008, 233, 891-896. [CrossRef]

20. Jiang, Y.; Shan, S.; Gan, T.; Zhang, X.; Lu, X.; Hu, H.; Wu, Y.; Sheng, J.; Yang, J. Effects of cisplatin on the contractile function of thoracic aorta of Sprague-Dawley rats. BioMed Rep. 2014, 2, 893-897. [CrossRef]

21. Nemmar, A.; Al-Salam, S.; Yuvaraju, P.; Beegam, S.; Ali, B.H. Emodin mitigates diesel exhaust particles-induced increase in airway resistance, inflammation and oxidative stress in mice. Respir. Physiol. Neurobiol. 2015, 215, 51-57. [CrossRef]

22. Zainalabidin, S.; Budin, S.B.; Ramalingam, A.; Lim, Y.C. Aortic remodelling in chronic nicotine-administered rat. Korean J. Physiol. Pharmacol. 2014, 18, 411-418. [CrossRef]

23. Tsikas, D. Methods of quantitative analysis of the nitric oxide metabolites nitrite and nitrate in human biological fluids. Free Radic. Res. 2005, 39, 797-815. [CrossRef]

24. Nemmar, A.; Al-Salam, S.; Beegam, S.; Yuvaraju, P.; Oulhaj, A.; Ali, B.H. Water-Pipe Smoke Exposure-Induced Circulatory Disturbances in Mice, and the Influence of Betaine Supplementation Thereon. Cell. Physiol. Biochem. 2017, 41, 1098-1112. [CrossRef]

25. Nemmar, A.; Al-Salam, S.; Beegam, S.; Yuvaraju, P.; Ali, B.H. Thrombosis, systemic and cardiac oxidative stress and DNA damage induced by pulmonary exposure to diesel exhaust particles, and the effect of nootkatone thereon. Am. J. Physiol. Heart Circ. Physiol. 2018, 314, H917-H927. [CrossRef]

26. Nemmar, A.; Al, H.A.; Al, H.N.; Yuvaraju, P.; Beegam, S.; Yasin, J.; Elwasila, M.; Ali, B.H.; Adeghate, E. Early pulmonary events of nose-only water pipe (shisha) smoking exposure in mice. Physiol. Rep. 2015, 3, e12258. [CrossRef]

27. Al Suleimani, Y.M.; Al Mahruqi, A.S.; Al, Z.M.; Shalaby, A.; Ashique, M.; Nemmar, A.; Ali, B.H. Effect of diesel exhaust particles on renal vascular responses in rats with chronic kidney disease. Environ. Toxicol. 2017, 32, 541-549. [CrossRef]

28. Nemmar, A.; Yuvaraju, P.; Beegam, S.; Yasin, J.; Kazzam, E.E.; Ali, B.H. Oxidative stress, inflammation, and DNA damage in multiple organs of mice acutely exposed to amorphous silica nanoparticles. Int. J. Nanomed. 2016, 11, 919-928. [CrossRef]

29. Nemmar, A.; Al-Salam, S.; Yuvaraju, P.; Beegam, S.; Yasin, J.; Ali, B.H. Chronic Exposure to Water-Pipe Smoke Induces Alveolar Enlargement, DNA Damage and Impairment of Lung Function. Cell. Physiol. Biochem. 2016, 38, 982-992. [CrossRef]

30. Nemmar, A.; Beegam, S.; Yuvaraju, P.; Yasin, J.; Tariq, S.; Attoub, S.; Ali, B.H. Ultrasmall superparamagnetic iron oxide nanoparticles acutely promote thrombosis and cardiac oxidative stress and DNA damage in mice. Part. Fibre Toxicol. 2016, 13, 22. [CrossRef]

31. Nemmar, A.; Al-Salam, S.; Beegam, S.; Yuvaraju, P.; Ali, B.H. The acute pulmonary and thrombotic effects of cerium oxide nanoparticles after intratracheal instillation in mice. Int. J. Nanomed. 2017, 12, 2913-2922. [CrossRef]

32. Wingard, C.J.; Walters, D.M.; Cathey, B.L.; Hilderbrand, S.C.; Katwa, P.; Lin, S.; Ke, P.C.; Podila, R.; Rao, A.; Lust, R.M.; et al. Mast cells contribute to altered vascular reactivity and ischemia-reperfusion injury following cerium oxide nanoparticle instillation. Nanotoxicology 2011, 5, 531-545. [CrossRef]

33. Siti, H.N.; Kamisah, Y.; Kamsiah, J. The role of oxidative stress, antioxidants and vascular inflammation in cardiovascular disease (a review). Vascul. Pharmacol. 2015, 71, 40-56. [CrossRef] 
34. Xue, M.; Qian, Q.; Adaikalakoteswari, A.; Rabbani, N.; Babaei-Jadidi, R.; Thornalley, P.J. Activation of NF-E2-related factor-2 reverses biochemical dysfunction of endothelial cells induced by hyperglycemia linked to vascular disease. Diabetes 2008, 57, 2809-2817. [CrossRef]

35. Teasdale, J.E.; Newby, A.C.; Timpson, N.J.; Munafo, M.R.; White, S.J. Cigarette smoke but not electronic cigarette aerosol activates a stress response in human coronary artery endothelial cells in culture. Drug Alcohol Depend. 2016, 163, 256-260. [CrossRef]

36. Manke, A.; Wang, L.; Rojanasakul, Y. Mechanisms of nanoparticle-induced oxidative stress and toxicity. BioMed Res. Int. 2013, 2013, 942916. [CrossRef]

37. Ali, D.; Alarifi, S.; Alkahtani, S.; AlKahtane, A.A.; Almalik, A. Cerium Oxide Nanoparticles Induce Oxidative Stress and Genotoxicity in Human Skin Melanoma Cells. Cell Biochem. Biophys. 2015, 71, 1643-1651. [CrossRef]

38. Benameur, L.; Auffan, M.; Cassien, M.; Liu, W.; Culcasi, M.; Rahmouni, H.; Stocker, P.; Tassistro, V.; Bottero, J.Y.; Rose, J.; et al. DNA damage and oxidative stress induced by $\mathrm{CeO}_{2}$ nanoparticles in human dermal fibroblasts: Evidence of a clastogenic effect as a mechanism of genotoxicity. Nanotoxicology 2015, 9, 696-705. [CrossRef]

39. Preaubert, L.; Courbiere, B.; Achard, V.; Tassistro, V.; Greco, F.; Orsiere, T.; Bottero, J.Y.; Rose, J.; Auffan, M.; Perrin, J. Cerium dioxide nanoparticles affect in vitro fertilization in mice. Nanotoxicology 2016, 10, 111-117.

40. Courbiere, B.; Auffan, M.; Rollais, R.; Tassistro, V.; Bonnefoy, A.; Botta, A.; Rose, J.; Orsiere, T.; Perrin, J. Ultrastructural interactions and genotoxicity assay of cerium dioxide nanoparticles on mouse oocytes. Int. J. Mol. Sci. 2013, 14, 21613-21628. [CrossRef]

(C) 2019 by the authors. Licensee MDPI, Basel, Switzerland. This article is an open access article distributed under the terms and conditions of the Creative Commons Attribution (CC BY) license (http://creativecommons.org/licenses/by/4.0/). 